\title{
Produção de matéria seca de forragem e acúmulo de nutrientes em pastagem anual de inverno tratada com esterco líquido de suínos
}

\author{
Forage dry matter production and nutrient uptake of a hibernal pasture under \\ application of pig slurry
}

\author{
Joice Mari Assmann' João Alfredo Braida ${ }^{\mathrm{II}}$ Luís César Cassol $^{\mathrm{I}}$ \\ Emanuelle Cavazini Magiero ${ }^{\mathrm{I}}$ Claudia Manteli ${ }^{\mathrm{I}}$ Ederson Griz $^{\mathrm{II}}$
}

\section{RESUMO}

O Esterco líquido de suínos (ELS) pode ser usado como fertilizante orgânico, mas seu uso incorreto pode contaminar o solo e os mananciais de água. O objetivo deste trabalho foi avaliar o efeito da adição de nutrientes ao solo, através do ELS, sobre a produção de matéria seca (MS) e o acúmulo de nutrientes de uma pastagem de aveia branca+azevém (Avena sativa + Lolium multiflorum). Um experimento foi realizado de 2004 a 2006, no campo experimental da UTFPR, em Pato Branco, Paraná, Brasil. O solo era um Latossolo Vermelho distroférrico. Diferentes doses $\left(0,20,40,80\right.$ e $\left.120 \mathrm{~m}^{3} \mathrm{ha}^{-1}\right)$ de ELS foram aplicadas na pastagem, aos 20 e 61 dias após a emergência (DAE) da pastagem, em 2004, e aos 30 e 67DAE, em 2005. Outras duas aplicações foram realizadas nas culturas de verão, milho em 2004 e soja em 2005, respectivamente. A maior produção de MS foi obtida com a dose de $120 \mathrm{~m}^{3} \mathrm{ha}^{-1}$ de ELS, tanto no primeiro, quanto no segundo ano. A absorção de nutrientes pelas plantas respondeu de forma linear à aplicação de esterco líquido de suínos.

Palavras-chave: adubação orgânica, fertilidade do solo, dejetos suínos, poluição ambiental.

\section{ABSTRACT}

The pig slurry can be used as an organic fertilizer but its improper use can contaminate water and soil. The objective of this study was to evaluate the effect of nutrient addition to the soil on pasture oat + ryegrass (Avena sativa + Lolium multiflorum) dry matter production and nutrient uptake. One experiment was carried out from 2004 to 2006, installed in the experimental farm of UTFPR in Pato Branco, Paraná State, Brazil. The soil was an Oxisol (Latossolo Vermelho distroférrico, Brazil systems). Different rates (0, 20, 40, 80 and $120 \mathrm{~m}^{3} \mathrm{ha}^{-1}$ ) of pig slurry were applied in the pasture. The pig slurry applications were performed 20 and 61 days after emergence (DAE) of pasture, in 2004, and 30 and 67DAE of pasture in 2005. Another two applications were performed in summer crops, corn in 2004 and soybean in 2005. In both years the rate $120 \mathrm{~m}^{3} \mathrm{ha}^{-1}$ of pig slurry resulted in the highest dry matter production. The nutrient uptake by plants responded in a linear manner to pig slurry application.

Key words: organic manure, soil fertility, pig slurry, environmental pollution.

\section{INTRODUÇÃO}

A criação de suínos em confinamento é considerada uma atividade de alto potencial poluidor, especialmente pela elevada produção de dejetos líquidos, que incluem, em sua composição, fezes, urina e restos de ração com elevados teores de nutrientes e de microorganismos. Quando lançados no ambiente, sem o devido controle e tratamento, esses dejetos podem tornar-se agentes poluentes da água e do solo. Por outro lado, os dejetos de suínos podem ser utilizados na agricultura como fonte de nutrientes para as plantas, diminuindo os custos de produção e, desde que corretamente manejados, diminuindo os riscos de contaminação ambiental, com reflexos sociais e econômicos (CHASE et al., 1991; PORT et al., 2003; BASSO et al., 2005).

Entretanto, estudos recentes, em regiões onde esta prática é comumente usada pelos agricultores, têm demonstrado que ainda existem riscos ao ambiente. A despeito da absorção dos nutrientes

'Universidade Tecnológica Federal do Paraná (UTFPR), Pato Branco, PR, Brasil.

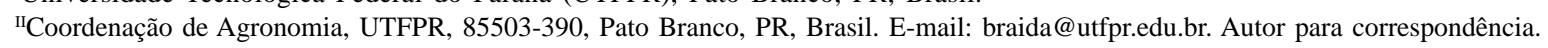

IIICentro Universitário Leonardo da Vinci, Chopinzinho, PR, Brasil. 
pelas culturas, da intensa atividade microbiana e da capacidade de adsorção à fração coloidal do solo, parte dos constituintes dos dejetos, ou o resultado da sua transformação, pode atingir os mananciais de água por lixiviação (BASSO et al., 2005) ou escoamento superficial (CERETTA et al., 2005a), acumular no solo (MATTIAS, 2006) atingindo níveis perigosos à saúde vegetal, animal ou humana e/ou perder-se por volatilização (PORT et al., 2003). Assim, estudos que avaliem o comportamento dos nutrientes no solo e sua absorção pelas plantas, após aplicação de dejetos, ainda são necessários.

No Brasil, especialmente na Região Sul, a suinocultura é, tipicamente, uma atividade de pequenas propriedades rurais e está aliada à produção de grãos e de leite. Nessas propriedades, a utilização dos dejetos como fonte de nutrientes, principalmente na adubação de pastagens anuais de inverno, muito utilizadas em sistemas de integração com lavouras de verão e produção leiteira, é uma ótima alternativa de redução dos custos de produção.

A região sudoeste do Paraná caracteriza-se por apresentar 93\% dos estabelecimentos rurais com menos de 50ha. As produções de leite e de suínos aparecem, respectivamente, em 75 e $73 \%$ dos estabelecimentos (PERIN et al., 2001). Em muitos destes, a produção de leite e de suínos está integrada com a produção de grãos, sendo que as áreas ocupadas por lavouras anuais no verão cedem lugar às pastagens no inverno.

Os benefícios do uso de esterco líquido de suínos (ELS) na adubação de pastagens foram demonstrados por CERETTA et al. (2005b), que observaram incrementos na produção de massa seca de aveia preta de 128, 223 e 331\%, no primeiro ano, e de 43,87 e $174 \%$ no segundo ano, respectivamente, para doses de 20, 40 e $80 \mathrm{~m}^{3}$ ha $^{-1}$ de ELS.

Os maiores rendimentos das plantas cultivadas com aplicação de ELS, em geral, são frutos de uma melhoria no seu estado nutricional, especialmente no que se refere ao nitrogênio. CERETTA et al. (2005b), em experimento num Argissolo distrófico arênico com diferentes doses de ELS, durante dois anos na rotação de aveia preta/milho/nabo forrageiro, observaram incrementos na absorção de $\mathrm{N}$ de 229 a $339 \%$, de $\mathrm{P}$ de $478 \%$ e de K de 117 a $520 \%$ para a dose de $80 \mathrm{~m}^{3} \mathrm{ha}^{-1}$, em relação à testemunha. DURIGON et al. (2002), trabalhando em pastagem natural durante quatro anos, obtiveram um aproveitamento do $\mathrm{N}$ de 29 e 23\%, do P de 8,1 e 5,8\%, do K de 45 e 32\%, do Ca de 43 e $29 \%$ e do $\mathrm{Mg}$ de 70 e $50 \%$ para as doses de 20 e $40 \mathrm{~m}^{3} \mathrm{ha}^{-1}$ de ELS, respectivamente. Em um Argissolo Vermelho distrófico arênico, BARCELLOS (1991) observou pequenas diferenças na absorção de $\mathrm{P}$ (38\%) e de $\mathrm{K}$ (6\%) pelo milho, quando comparou a aplicação de $40 \mathrm{~m}^{3}$ ha-1 de ELS com a testemunha sem aplicação de esterco.

A qualidade nutricional das plantas forrageiras é muito variável e dependente de vários fatores, dentre os quais a fertilidade do solo e as adubações realizadas. Assim, o fornecimento de quantidades adequadas de nutrientes, via ELS, pode incrementar a qualidade nutricional da forragem, melhorando o desempenho e/ou a produtividade dos animais.

Nesse contexto, o presente estudo teve por objetivo avaliar a eficácia do uso de ELS na produção de matéria seca (MS) e acúmulo de nutrientes em uma pastagem de inverno, constituída de um consórcio de aveia branca (Avena sativa) e azevém (Lolium multiflorum), em um Latossolo Vermelho distroférrico cultivado no sistema plantio direto.

\section{MATERIAL E MÉTODOS}

Um experimento foi conduzido entre maio de 2004 e maio de 2006, na área experimental do Curso de Agronomia, da Universidade Tecnológica Federal do Paraná (UTFPR), Campus Pato Branco, situada em Pato Branco, Paraná, numa altitude de $730 \mathrm{~m}$, latitude de $26^{\circ} 41^{\prime} \mathrm{S}$ e longitude de $56^{\circ} 07^{\prime} \mathrm{W}$. O solo da área pertence à unidade de mapeamento LVdf2 - Latossolo Vermelho distroférrico (BHERING et al., 2008), apresentando textura argilosa e, na camada de 0 a $0,20 \mathrm{~m}$ de profundidade, antes da instalação do experimento, apresentava as seguintes características químicas:

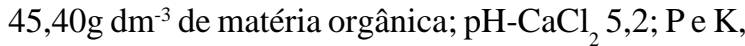
extraídos por Mehlich I, de 24,14mg dm $\mathrm{m}^{-3}$ e $0,24 \mathrm{cmol}$ $\mathrm{dm}^{-3}$, respectivamente; Ca, $\mathrm{Mg}$ e Al, extraídos por $\mathrm{KCl}$ $1 \mathrm{M}$, de 5,40, 3,32 e 0,00 $\mathrm{cmol} \mathrm{dm}^{-3}$, respectivamente; e $\mathrm{CTC}_{\mathrm{pH} 7,0}$ de $13,86 \mathrm{cmol}_{\mathrm{c}} \mathrm{dm}^{-3}$.

O delineamento experimental foi o de blocos completos ao acaso, com quatro repetições, sendo que cada unidade experimental media $16 \mathrm{~m}^{2}$ ( $\left.4 \mathrm{x} 4 \mathrm{~m}\right)$. Os tratamentos consistiram das seguintes doses de ELS: 0, 20, 40, 80 e $120 \mathrm{~m}^{3} \mathrm{ha}^{-1}$. No período em análise, foram conduzidos dois ciclos da pastagem, na seguinte sequência de culturas: aveia branca+azevém/milho (Zea mays)/aveia branca+azevém/soja (Glycine max). Nesse período, foram realizadas seis aplicações de esterco, sendo três no primeiro ano (2004): aos 20 e 61 dias após a emergência (DAE) da pastagem e uma aos 30DAE do milho; e três no segundo ano (2005): aos 30 e 67DAE da pastagem e uma aos 30DAE da soja. As aplicações aos 61DAE (em 2004) e aos 67DAE (em 2005) ocorreram após a pastagem ter sido cortada a $0,10 \mathrm{~m}$ de altura para simular pastejo, com posterior retirada do 
material da superfície do solo. As seis aplicações de ELS constituíram-se da dose cheia, conforme o tratamento. Algumas características médias do ELS utilizado em cada cultura são apresentadas na tabela 1 . O esterco, em todas as aplicações, foi distribuído uniformemente em toda a parcela usando-se regadores plásticos de 10L de capacidade.

A semeadura da aveia e do azevém, nos dois anos, foi realizada no sistema plantio direto, com semeadora adubadora, utilizando-se uma proporção de $80 \mathrm{~kg} \mathrm{ha}^{-1}$ de aveia branca cv. 'IPR 126' e $20 \mathrm{~kg} \mathrm{ha}^{-1} \mathrm{de}$ azevém, com espaçamento entre linhas de $0,17 \mathrm{~m}$, nos dias 28 de maio de 2004 (primeiro ano) e 30 de maio de 2005 (segundo ano). As culturas de verão, milho e soja, foram semeadas, respectivamente, nos dias 07 de outubro de 2004 e 31 de outubro de 2005, também no sistema plantio direto.

Para a avaliação da produção da pastagem, aos 61 e 108DAE, em 2004, e aos 67 e 129DAE, em 2005, em uma área útil de $0,50 \mathrm{~m}^{2}$ por parcela, coletaram-se amostras de plantas para determinação de matéria seca, após secagem em estufa a $65^{\circ} \mathrm{C}$. Em seguida, o material foi moído em moinho de faca tipo Willey (<40 mesh) e realizada a digestão sulfúrica para determinação da concentração de nutrientes no tecido vegetal, sendo o $\mathrm{N}$ total determinado em destilador de arraste de vapor semimicro Kjeldhal (TEDESCO et al., 1995). Usando uma amostra da alíquota obtida na digestão, foram determinados os teores totais de $\mathrm{P}, \mathrm{K}$, Ca e $\mathrm{Mg}$ por fotocolorimetria, fotometria de chama e espectrofotometria de absorção atômica, respectivamente. Com os dados de biomassa da pastagem e concentração dos nutrientes, foi calculado o acúmulo de nutrientes na parte aérea. $O$ teor de proteína bruta (PB) da pastagem foi calculado multiplicando-se a concentração de $\mathrm{N}$ por 6,25 , considerando-se que a proteína contém cerca de $16 \%$ de N .

Os resultados obtidos foram submetidos à análise de variância. Quando houve variação significativa pelo teste $\mathrm{F}$ a $5 \%$, realizou-se a análise de regressão, escolhendo-se o modelo com base na significância $(\mathrm{P}<0,05)$ e no coeficiente de determinação. O programa estatístico utilizado foi o STATGRAPHICS ${ }^{\circledR}$.

\section{RESULTADOS E DISCUSSÃO}

A utilização de ELS aumentou a produção de MS da pastagem nos dois anos de cultivo (Figura 1). No primeiro ano, comparando-se a testemunha (sem ELS) com a maior dose de ELS $\left(120 \mathrm{~m}^{3} \mathrm{ha}^{-1}\right)$, o incremento de MS foi de 147 e $112 \%$, aos 61 e aos 108DAE,

Tabela 1 - Teores de nitrogênio (N), fósforo (P), potássio (K) e matéria seca (MS) e pH do esterco líquido de suínos e quantidades de nutrientes aplicadas, de acordo com a dose utilizada (20, 40, 80 e $\left.120 \mathrm{~m}^{3} \mathrm{ha}^{-1}\right)$, para cada cultura da sucessão aveia branca (Avena sativa) +azevém (Lolium multiflorum)/milho (Zea mays)/aveia branca+azevém/soja (Glycine max). Pato Branco, PR, 2009.

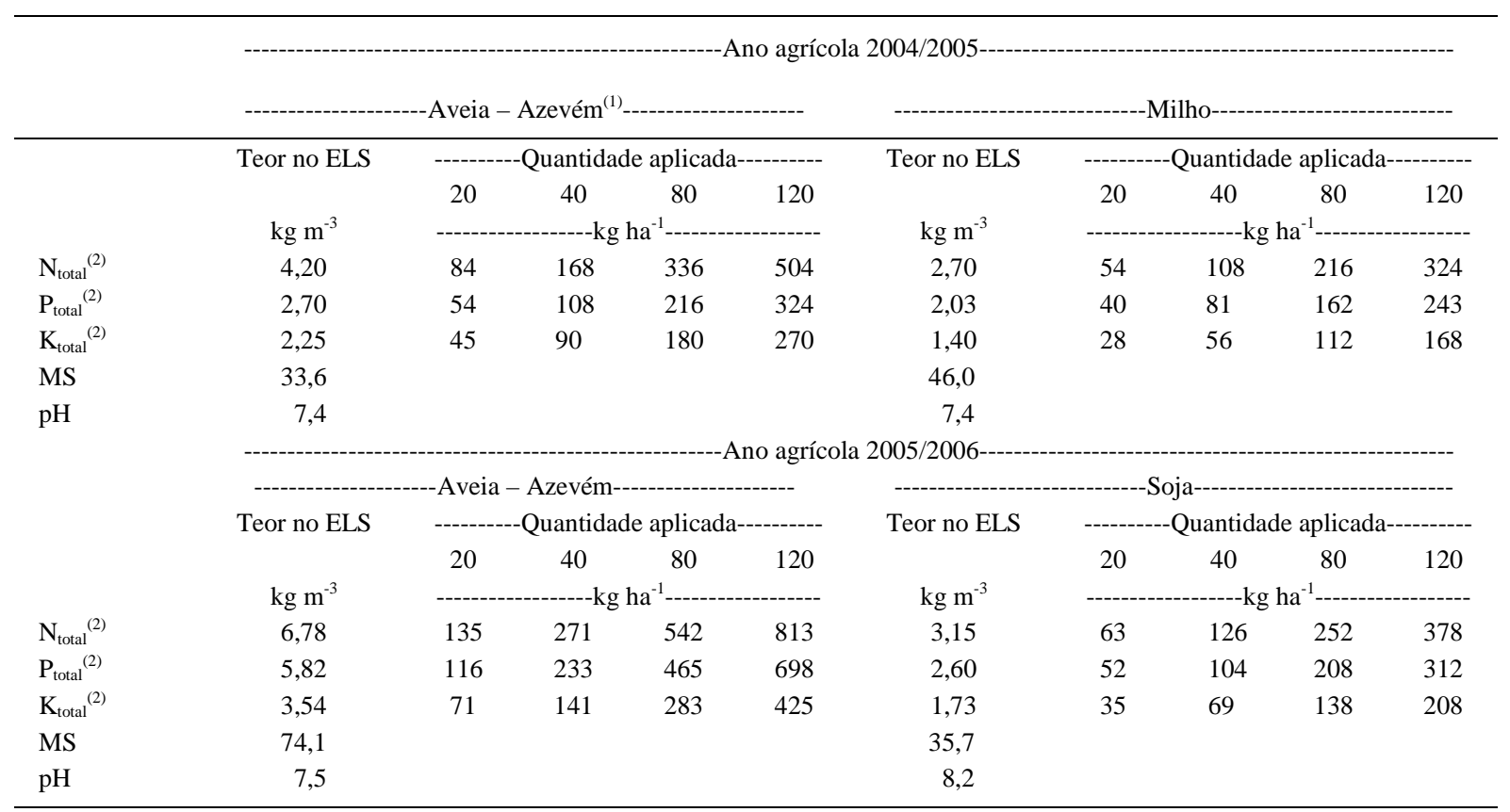

(1) Para a pastagem, foram realizadas duas aplicações. Os resultados mostrados aqui são os valores médios de duas amostragens.

(2) Análise e cálculos em base úmida. 


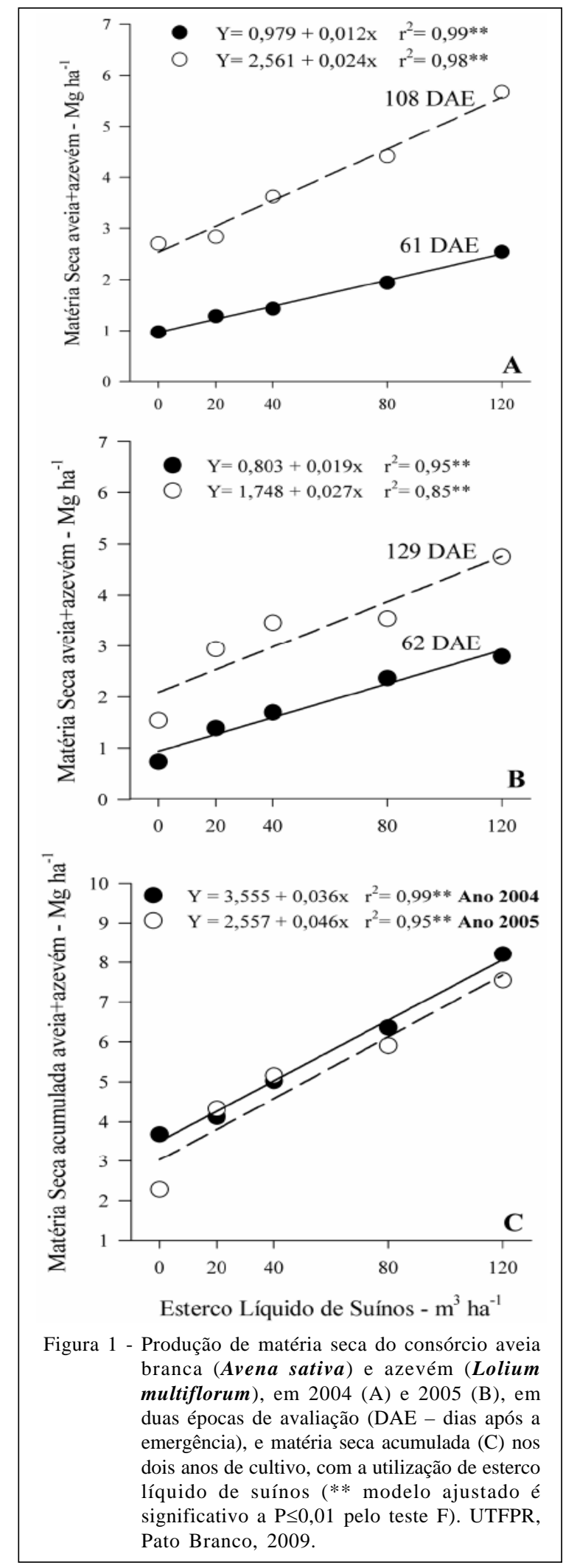

respectivamente. Isso significou uma produção de 2,42Mg ha- ${ }^{-1}$ aos 61DAE e de 5,44Mg ha-1 aos 108DAE para o tratamento com $120 \mathrm{~m}^{3}$ ha $^{-1}$ de ELS, contra 0,94 e 2,56 $\mathrm{Mg} \mathrm{ha}^{-1}$, nas mesmas datas, na área sem uso de ELS (Figura 1A). No segundo ano, o incremento de MS, em relação à testemunha, foi de $284 \%$ aos $62 \mathrm{DAE}$ e $185 \%$ aos $129 \mathrm{DAE}$, com a dose de $120 \mathrm{~m}^{3} \mathrm{ha}^{-1}$, resultando em incremento de $2,06 \mathrm{Mg} \mathrm{ha}^{-1}$ nos $62 \mathrm{DAE}$ e 3,22Mg ha-1 aos 129DAE em relação à área sem uso de ELS (Figura 1B). Os maiores incrementos obtidos no segundo ano, possivelmente, devem-se ao maior teor de matéria seca do dejeto utilizado, que foi 45,3\% superior ao do dejeto utilizado no primeiro ano (Tabela 1). Além disso, houve diferenças nas temperaturas médias e precipitações observadas nos dois anos, especialmente nos meses de agosto e setembro, período em que ocorreram as avaliações (Figura 2). As médias de temperatura (máximas e mínimas) e de precipitação durante o período experimental foram obtidas na Estação Meteorológica do IAPAR (Instituto Agronômico do Paraná), distante 10km da área do local do experimento.

AITA et al. (2006), em experimento realizado com diferentes plantas de cobertura, concluíram que a aplicação de dejetos de suínos proporcionou incremento significativo na produção de MS de aveia em até $109 \%$ em relação à testemunha, com o uso de $80 \mathrm{~kg} \mathrm{ha}^{-1}$ de ELS. DURIGON et al. (2002) obtiveram incrementos de 44 e $70 \%$ na produção de MS em pastagem natural adubada com 20 e $40 \mathrm{~m}^{3}$ ha $^{-1}$ de dejetos, respectivamente, corroborando os resultados aqui apresentados.

A produção de matéria seca acumulada (MSA), nos dois anos, aumentou linearmente em relação às doses de ELS aplicadas, atingindo 7,87 e 8,08 $\mathrm{Mg} \mathrm{ha}^{-1}$, respectivamente, nos anos de 2004 e de 2005, com a dose de $120 \mathrm{~m}^{3} \mathrm{ha}^{-1}$. Disso resultou um incremento de $121 \%$ em 2004 e de $215 \%$ em 2005, comparado com a área sem utilização de ELS, na qual a produção de MSA foi de 3,55 $\mathrm{Mg} \mathrm{ha}^{-1}$ em 2004 e de 2,56 Mg ha-1 em 2005 (Figura 1C). Esses dados corroboram aqueles obtidos por ASSMANN et al. (2007), que observaram uma produção de MSA em pastagem de aveia+azevém de 6,55Mg ha-1 ${ }^{-1}$ com aplicação de $80 \mathrm{~m}^{3} \mathrm{ha}^{-1}$, em um período de 156 dias. Entretanto, o aumento percentual de MSA foi de apenas 34\% em relação à testemunha, inferior ao obtido neste trabalho, justificado pelos autores como devido a um déficit hídrico durante parte do período experimental e que afetou o segundo corte da pastagem, e teria ocasionado perdas de $\mathrm{N}$ por volatilização, uma vez que $70 \%$ do $\mathrm{N}$ presente no ELS encontra-se na forma amoniacal $\left(\mathrm{NH}_{4}^{+}\right)$(SHERER et al., 1996).

Como se pode observar na Figura 1C, o uso de ELS resultou em ganhos de 36 e $46 \mathrm{~kg} \mathrm{MS} \mathrm{m}^{-3}$ de ELS aplicado para o primeiro e o segundo ano, 


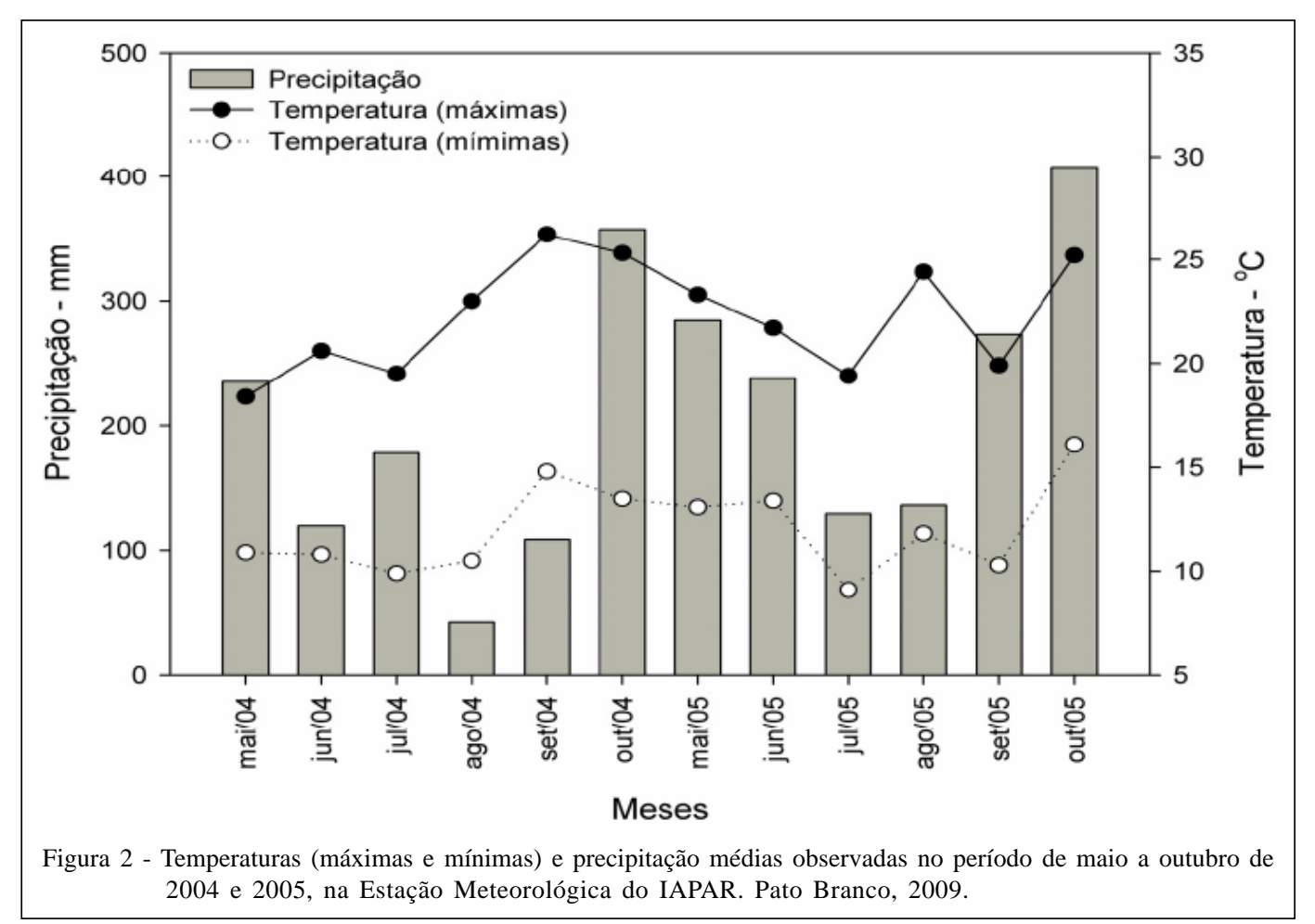

respectivamente. Já CERETTA et al. (2005b) observaram acréscimos de 35 e $43 \mathrm{~kg} \mathrm{MS} \mathrm{m}^{-3}$ de ELS aplicado, ao passar de 20 para $80 \mathrm{~m}^{-3}$ de ELS, muito semelhante aos dados obtidos neste experimento. O maior incremento na produção de MS observado no segundo ano, no presente estudo, deve-se à maior concentração de matéria seca no ELS utilizado e, provavelmente, a um possível efeito residual das aplicações do primeiro ano, além das diferenças climáticas observadas.

$\mathrm{O}$ incremento na concentração de $\mathrm{N}$ com a aplicação de ELS (Figuras 3A e 3B) promoveu melhoria na qualidade da pastagem, evidenciada pela produção de $\mathrm{PB}$ por hectare (Figuras 3C e 3D), uma vez que o teor de $\mathrm{N}$ na pastagem está diretamente relacionado com o teor de proteína (em média 16\% de N na PB). Nos dois anos de avaliação, o uso do ELS promoveu um incremento significativo de PB na MS da pastagem de aveia+azevém, respondendo de forma linear em relação às doses aplicadas. $\mathrm{O}$ acúmulo de $\mathrm{PB}$, com o uso de $120 \mathrm{~m}^{3} \mathrm{ha}^{-1}$ de ELS, foi de $528 \mathrm{~kg} \mathrm{ha}^{-1}$ aos 61DAE e de 715 aos 108DAE em 2004, contra 139 e $228 \mathrm{~kg} \mathrm{ha}^{-1}$, aos 61DAE e 108DAE na área sem uso de ELS (Figura 3C). No ano de 2005, aplicando-se $120 \mathrm{~m}^{3} \mathrm{ha}^{-1}$ de ELS, a produção foi de $664 \mathrm{~kg} \mathrm{ha}^{-1}$ aos 62DAE e de $673 \mathrm{~kg} \mathrm{ha}^{-1}$ aos 129DAE, contra 107 e 158kg ha-1, aos 62DAE e 129DAE, na área sem uso de ELS (Figura 3D).

No primeiro e no segundo ano de avaliações, a aplicação de ELS influenciou significativamente e de forma linear o acúmulo de fósforo e potássio na pastagem (Figura 4). O incremento de K na parte aérea foi de $294 \%$, em relação à testemunha, sendo que o melhor aproveitamento ocorreu antes do primeiro corte da pastagem, com incrementos de 203 e 383\% em relação à testemunha, respectivamente para 2004 e 2005, possivelmente em função do aumento da concentração de K na parte aérea, uma vez que aumentos menores foram obtidos para a produção de MS (Figuras 4A e 4B). $\mathrm{O}$ acúmulo médio de $\mathrm{K}$ foi de 58 e de $57 \mathrm{~kg} \mathrm{ha}^{-1}$, respectivamente, no primeiro e no segundo cultivo com o uso de $120 \mathrm{~m}^{3}$ ha $^{-1}$ de ELS. Ressalta-se ainda que esses acréscimos ocorreram mesmo estando o solo com teores de $\mathrm{K}$ em nível próximo ao considerado alto $\left(0,24 \mathrm{cmol}_{\mathrm{c}} \mathrm{dm}^{-3} \mathrm{de} \mathrm{K}\right)$ pela CQFS (2004).

Por sua vez, o incremento de $\mathrm{P}$ nos dois anos foi de $345 \%$ em relação à testemunha, sendo que no segundo ano obteve-se o maior incremento (430\%) em relação à testemunha (Figuras 4C e 4D). A maior absorção de $\mathrm{P}$ no segundo ano deve-se, além de ao maior teor de matéria seca do dejeto aplicado, à baixa solubilidade superficial do P no solo, especialmente no caso do ELS, em que aproximadamente dois terços do P encontram-se numa forma não solúvel em água, possivelmente fazendo parte de estruturas orgânicas (SCHERER et al., 1996). Assim, apenas uma terça parte do P estaria imediatamente disponível para as plantas logo após a aplicação. O restante do P-orgânico

Ciência Rural, v.39, n.8, nov, 2009. 


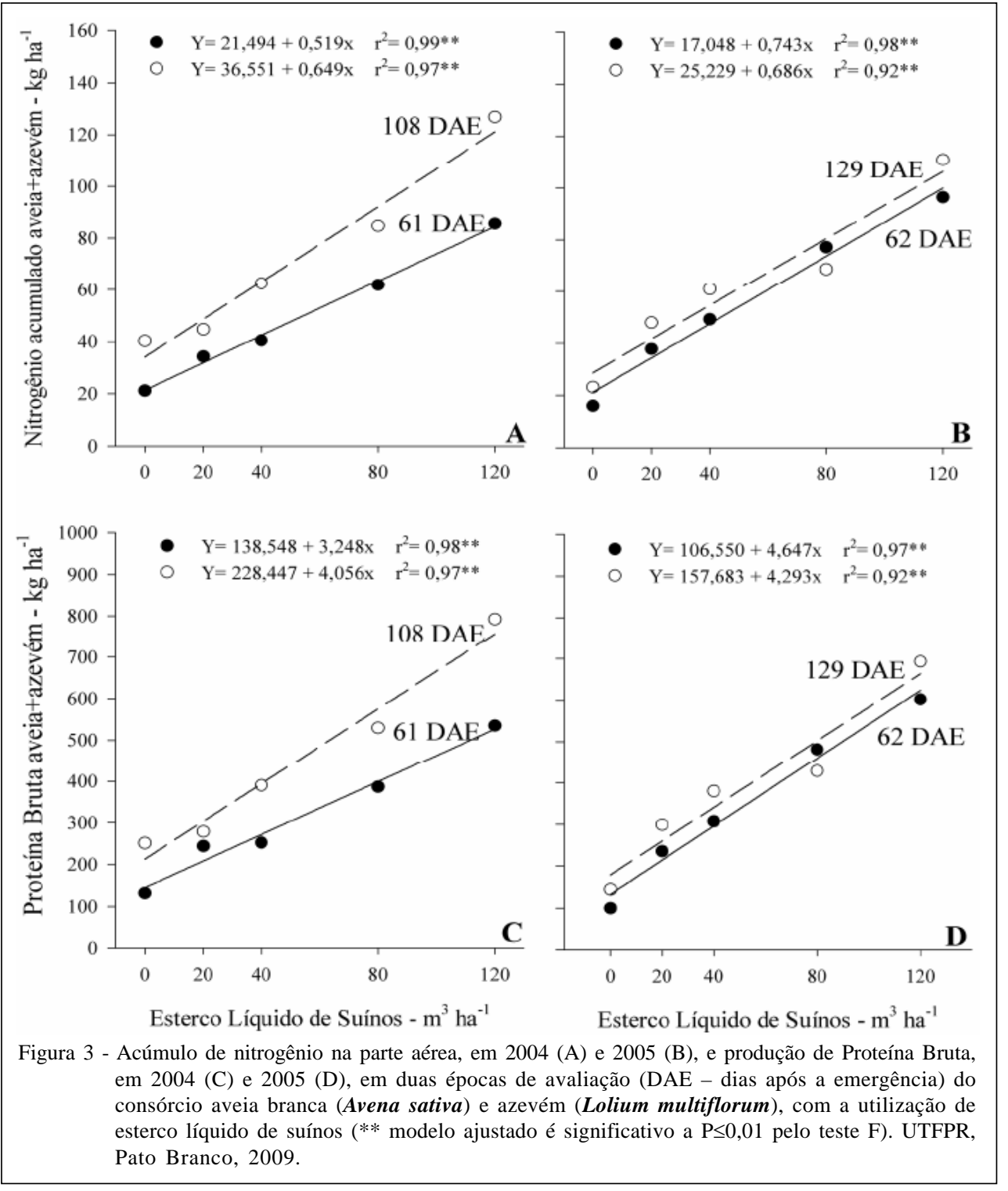

somente será aproveitado pelas plantas após a decomposição microbiológica (ALEXANDER, 1977), ocorrida com o passar do tempo, estando em sua maioria disponível no segundo ano de cultivo. $\mathrm{O}$ acúmulo de $\mathrm{P}$ na pastagem no primeiro ano atingiu valores de até $6,82 \mathrm{~kg} \mathrm{ha}^{-1}$ aos $61 \mathrm{DAE}$ e $15,50 \mathrm{~kg} \mathrm{ha}^{-1}$ na dose de $120 \mathrm{~m}^{3}$ $\mathrm{ha}^{-1}$. Enquanto isso, no segundo ano, o acúmulo de $\mathrm{P}$ foi de $8,51 \mathrm{~kg} \mathrm{ha}^{-1}$ aos $62 \mathrm{DAE}$ e de $14,98 \mathrm{~kg} \mathrm{ha}^{-1}$ aos 129DAE, na dose de $120 \mathrm{~m}^{3} \mathrm{ha}^{-1}$ de ELS. Do mesmo modo ao observado com o potássio, também neste caso os acréscimos ocorreram a partir de um solo com elevado teor de P no solo (24mg dm ${ }^{-3}$ de P Mehlich I), conforme a classificação da CQFS (2004).

Os acúmulos e incrementos de $\mathrm{P}$ e $\mathrm{K}$ encontrados neste trabalho estão muito próximos aos observados por CERETTA et al. (2005b), que obtiveram incrementos de 35, 70 e 139\% no teor de P e de 46, 81 e $117 \%$ no teor de $\mathrm{K}$ em relação à testemunha, para as doses de 20, 40 e $80 \mathrm{~m}^{3}$ ha $^{-1}$, respectivamente, durante dois anos da rotação aveia preta/milho/nabo forrageiro.

O acúmulo de cálcio e magnésio na pastagem foi influenciado significativamente pelo uso de ELS, observando-se um efeito linear em relação às doses aplicadas nos dois anos de cultivo (Figura 5). No primeiro ano, o incremento médio de Ca e de Mg foi de 165 e de 184\%, respectivamente, em relação à testemunha, para a dose de $120 \mathrm{~m}^{3} \mathrm{ha}^{-1}$. Já o incremento no segundo ano foi quase o dobro do primeiro, tanto para o Ca quanto para o Mg, com percentual de $420 \%$ 


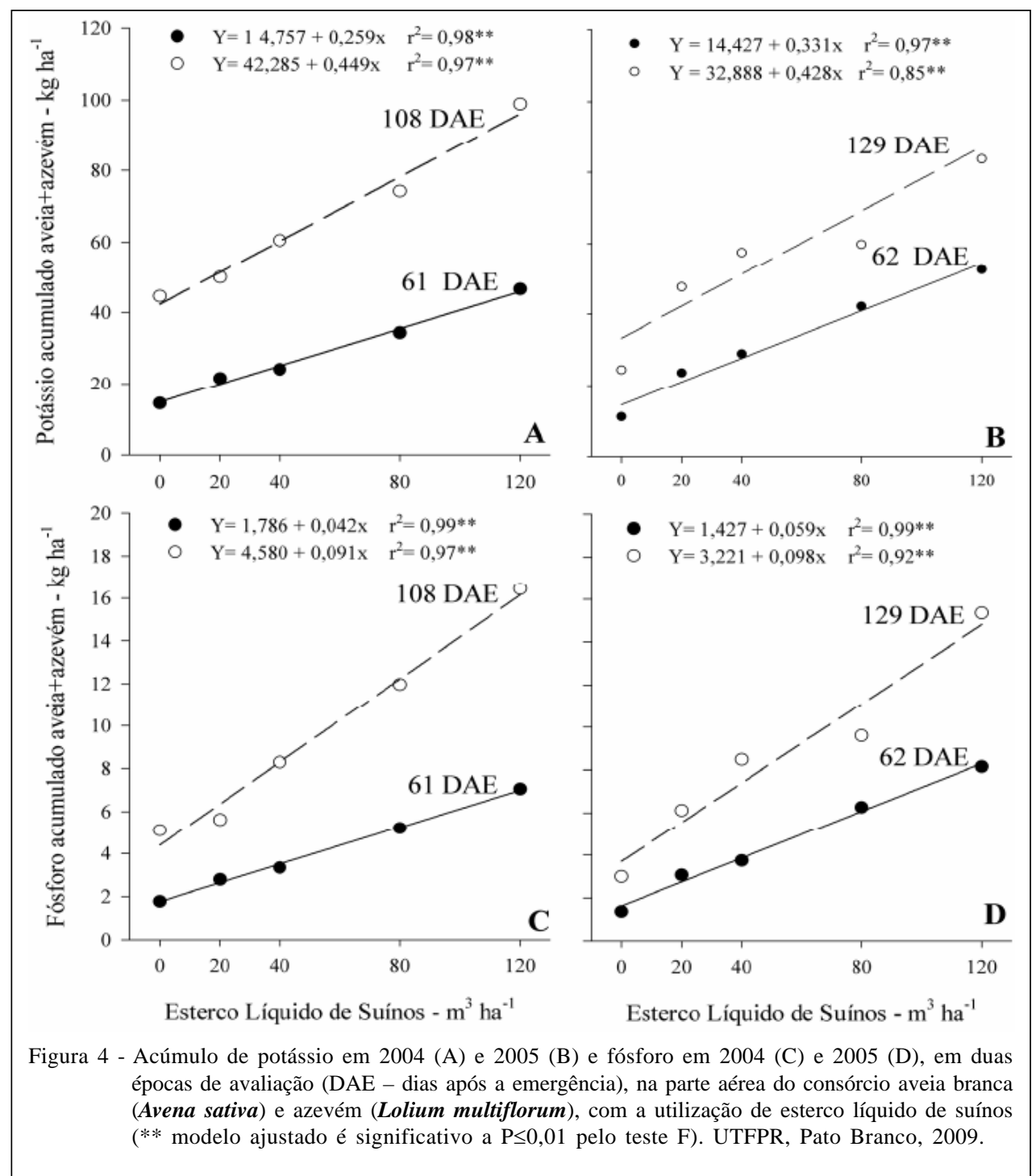

de Ca e $317 \%$ de $\mathrm{Mg}$, para a dose de $120 \mathrm{~m}^{3} \mathrm{ha}^{-1}$, em relação à testemunha. Esses incrementos levaram a um acúmulo de Ca e Mg no primeiro ano de até $15,60 \mathrm{~kg} \mathrm{ha}^{-1}$ de Ca e 10,78 $\mathrm{kg} \mathrm{ha}^{-1}$ de Mg aos 61DAE. Aos 108DAE, o acúmulo foi de $46,73 \mathrm{~kg} \mathrm{ha}^{-1}$ de Ca e de $14,38 \mathrm{~kg} \mathrm{ha}^{-1} \mathrm{de}$ Mg, para a dose de $120 \mathrm{~m}^{3} \mathrm{ha}^{-1}$, contra $6,21 \mathrm{~kg} \mathrm{ha}^{-1}$ de Ca, 3,82 $\mathrm{kg} \mathrm{ha}^{-1} \mathrm{de} \mathrm{Mg}$, aos 61DAE, e de 16,74kg ha-1 de Ca, 7,82 $\mathrm{kg} \mathrm{ha}^{-1}$ de $\mathrm{Mg}$, aos 108DAE. De acordo com a equação de regressão, cada $\mathrm{m}^{3} \mathrm{ha}^{-1}$ de ELS aplicado no segundo ano implicou um incremento médio de $0,229 \mathrm{~kg}$ $\mathrm{ha}^{-1}$ para Ca e de $0,106 \mathrm{~kg} \mathrm{ha}^{-1}$ para Mg na massa da forragem.

A maior absorção de nutrientes pela pastagem aveia+azevém, observada no segundo ano, deve-se ao efeito residual da aplicação dos dejetos, seja pela liberação lenta de alguns nutrientes ou pelo acúmulo de nutrientes no solo de um ano para o outro, bem como ao fato de, no segundo ano, em média, o esterco utilizado ter maior teor de matéria seca e, portanto, de acordo com as observações de BARCELLOS (1991), maiores teores de nutrientes.

\section{CONCLUSÕES}

A aplicação de esterco líquido de suínos afetou positivamente a produção de forragem e o acúmulo de nutrientes pela pastagem de aveia+azevém. A produção de matéria seca e o acúmulo de N, P, K, Ca e Mg pelas plantas da pastagem responderam de forma linear à aplicação de esterco líquido de suínos, para doses de até $120 \mathrm{~m}^{3} \mathrm{ha}^{-1}$.

Ciência Rural, v.39, n.8, nov, 2009. 


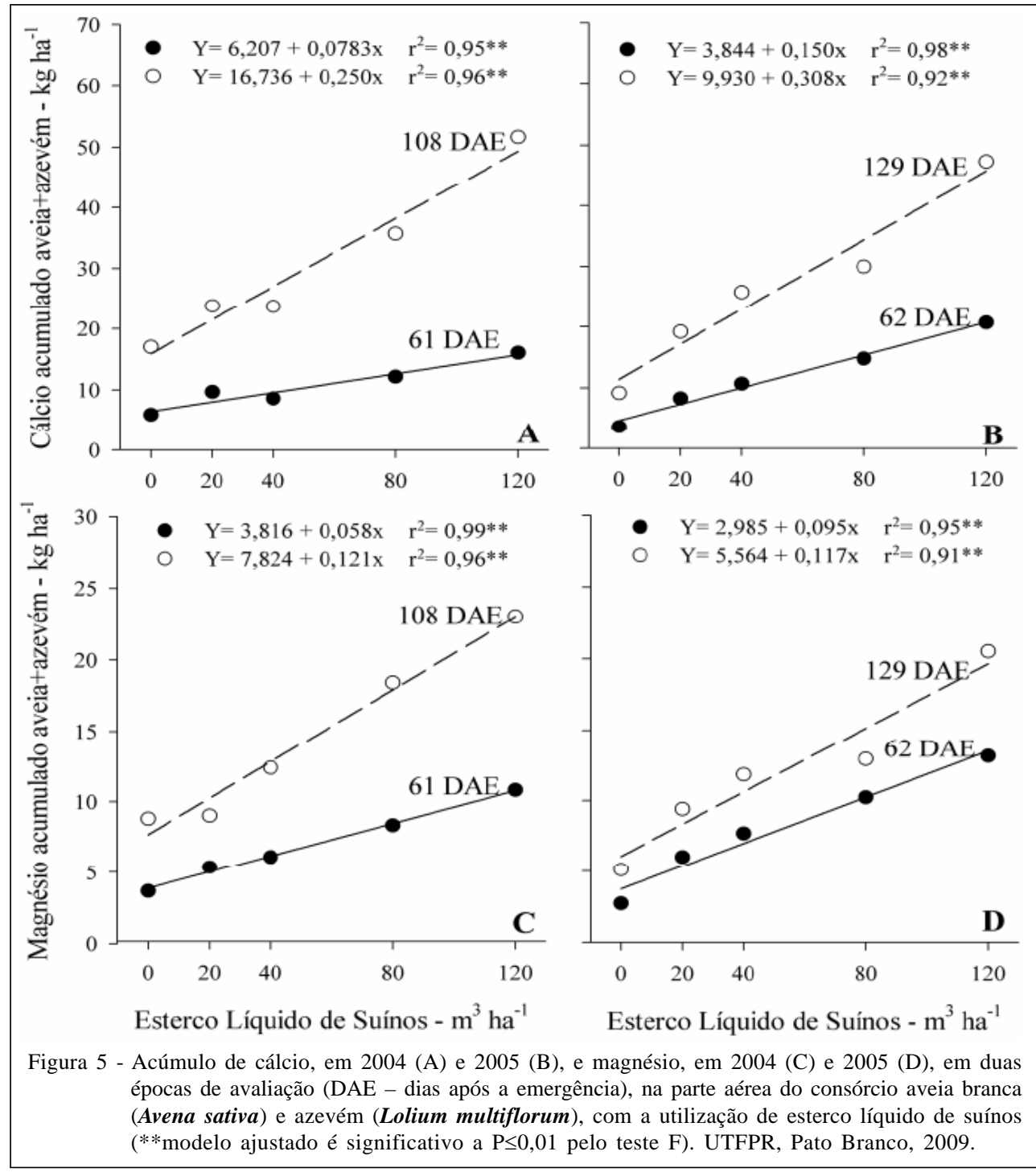

\section{REFERÊNCIAS}

AITA, C. et al. Dinâmica do nitrogênio no solo e produção de fitomassa por plantas de cobertura no outono/inverno com o uso de dejetos de suínos. Revista Brasileira de Ciência do Solo, v.30, n.5, p.901-910, 2006. Disponível em: <http:// www.scielo.br/scielo.php?script=sci_arttext\&pid=S0100$06832006000500016 \& \operatorname{lng}=$ en $\&$ nrm $=$ iso $>$. Acesso em 07 de jul. de 2009. ISSN 0100-0683. doi: 10.1590/S010006832006000500016

ALEXANDER, M. Intruction to soil microbiology. New York: J Wiley, 1977. 2v.

ASSMANN, T.S. et al. Desempenho da mistura forrageira de aveia-preta mais azevém e atributos químicos do solo em função da aplicação de esterco líquido de suínos. Revista Brasileira de Ciência do Solo, v.31, n.6, p.1515-1523, 2007. Disponível em: $<$ http://www.scielo.br/scielo.php?script=sci_arttext\&pid=S010006832007000600028\&lng=en\&nrm=iso $>$. Acesso em: 07 de jul. de 2009. ISSN 0100-0683. doi: 10.1590/S010006832007000600028.
BARCELLOS, L.A.R. Avaliação do potencial fertilizante do esterco líquido de bovinos. 1991. 108f. Dissertação (Mestrado em Agronomia) - Mestrado em Agronomia, Universidade Federal de Santa Maria, RS.

BASSO, C.J. et al. Dejeto líquido de suínos: II - perdas de nitrogênio e fósforo por percolação no solo sob plantio direto. Ciência Rural, v.35, n.6, p.1305-1312, 2005. Disponível em: <http:// www.scielo.br/scielo.php?script=sci_arttext \&pid=S010384782005000600012\&lng $=p t \& n r m=i s o>$. Acesso em: 07 de jul. de 2009. ISSN 0103-8478. doi: 10.1590/S010384782005000600012 .

BHERING, S.B. et al. Mapa de solos do Estado do Paraná: legenda atualizada. Rio de Janeiro : EMBRAPA/IAPAR, 2008. 74p.

CERETTA, C.A. et al. Dejeto líquido de suínos: I - perdas de nitrogênio e fósforo na solução escoada na superfície do solo, sob plantio direto. Ciência Rural, v.35, n.6, p.12961304, 2005a. Disponível em: <http://www.scielo.br/

Ciência Rural, v.39, n.8, nov, 2009. 
s cielo.php? script=sci_art text \& pid = S 0103 $84782005000600011 \& \operatorname{lng}=\mathrm{pt} \& \mathrm{nrm}=\mathrm{iso}>$. Acesso em: 07 de jul. de 2009. ISSN 0103-8478. doi: 10.1590/S010384782005000600011 .

CERETTA, C.A. et al. Produtividade de grãos de milho, produção de matéria seca e acúmulo de nitrogênio, fósforo e potássio na rotação aveia preta/milho/nabo forrageiro com aplicação de dejeto líquido de suínos. Ciência Rural, v.35, n.6, p.1287-1295, 2005b. Disponível em: <http://www.scielo.br/ scielo.php? script = sci_art text \& pid = S 0103 $84782005000600010 \& \operatorname{lng}=p t \& n r m=i s o>$. Acesso em: 07 de jul. de 2009. ISSN 0103-8478. doi: 10.1590/S010384782005000600010 .

CHASE, C. et al. Economic impact of varying swine manure application rates on continuous corn. Journal of Soil and Water Conservation, v.46, n.6, p.460-464, 1991.

CQFS - COMISSÃO DE QUÍMICA E FERTILIDADE DO SOLO - RS/SC. Manual de adubação e calagem para os estados do Rio Grande do Sul e Santa Catarina. Porto Alegre, SBCS, 2004. 400p.

DURIGON, R. et al. Produção de forragem em pastagem natural com o uso de esterco líquido de suínos. Revista Brasileira de Ciência do Solo, v.26, n.4, p.983-992, 2002.
MATTIAS, J.L. Metais pesados em solos sob aplicação de dejetos líquidos de suínos em duas microbacias hidrográficas de Santa Catarina. 2006. 164f. Tese (Doutorado em Ciência do Solo) - Curso de Doutorado em Ciência do Solo, Universidade Federal de Santa Maria, RS.

PERIN, E. et al. Agricultura familiar na região Sudoeste do Paraná: passado, presente e futuro. Londrina: IAPAR/ EMATER, 2001. 42p. (Projeto Paraná 12 meses).

PORT, O. et al. Perda de nitrogênio por volatilização de amônia com o uso de dejetos de suínos em plantio direto. Pesquisa Agropecuária Brasileira, v.38, n.7, p. 857-865, 2003. Disponível em: <http:// www.scielo.br/scielo.php?script $=$ sci_arttext\&pid $=$ S0100204X2003000700010\&lng=pt\&nrm=iso>. Acesso em: 07 de jul. de 2009. ISSN 0100-204X. doi: 10.1590/S0100-204X2003000700010.

SCHERER, E.E. et al. Avaliação da qualidade do esterco líquido de suínos da região Oeste Catarinense para fins de utilização como fertilizante. Florianopolis: EPAGRI, 1996. 46p. (Boletim técnico).

TEDESCO, M.J. et al. Análise de solo, plantas e outros materiais. Porto Alegre: Departamento de Solos da UFRGS, 1995. 174p. 